\title{
Factors Correlating with the Emotional and Behavioral Problems among Adolescents with Legal Problems
}

\author{
Sri Hartini ${ }^{1 *}$ D, Yuniske Penyami ${ }^{2}$, Yayi Prabandari ${ }^{3}$ (D) \\ ${ }^{1}$ Department of Pediatric and Maternity Nursing, Faculty of Medicine, Public Health, and Nursing, Universitas Gadjah Mada, \\ Yogyakarta, Indonesia; ${ }^{2}$ Master of Nursing, Faculty of Medicine, Public Health, and Nursing, Universitas Gadjah Mada, \\ Yogyakarta, Indonesia; ${ }^{3}$ Department of Health Behavior, Environment and Social Medicine, Faculty of Medicine, Public Health \\ and Nursing, Universitas Gadjah Mada, Yogyakarta, Indonesia
}

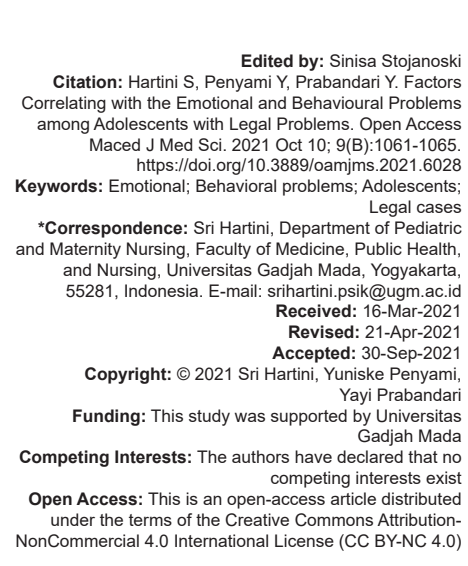

\section{Introduction}

Teenagers having problems with the law often experience cognitive, social-behavioral, and emotional problems. Adolescents who are in prison may experience a decrease in their cognitive control, cognitive function, and emotional regulation [1]. The cognitive function of children having a problem with the law changes in a negative direction.

Emotional and Behavioral Problems (EBP) includes psychosexual changes, peer problems, and risky behaviors such as drug abuse, smoking, alcohol consumption, antisocial behavior, failure to form selfidentity, problems with self-esteem, problems with moral development, and stress [2]. A study in Nepal shows that $17.03 \%$ of adolescents have experienced psychosocial dysfunction [3]. Behavioral and emotional problems have been experienced by $42 \%$ of the adolescents (1117 years old) in India and they are composed of $42 \%$ of conduct disorders and peer problems, $34 \%$ of emotional problems, and $24 \%$ of hyperactivity [4]. Another study found out that EBPs have been identified among $20 \%$ of adolescents in Taiwan [5]. Another report also indicates that the prevalence of emotional problems, conduct disorder, hyperactivity, and peer problems among the Indian teenagers is $5.9 \%, 28.2 \%, 6.5 \%$, and $15.2 \%$, respectively [6], and the prevalence of EBPs among the adolescents (12-18 years old) in Indonesia is $28.4 \%$ [7] consisting of emotional problems $(29.2 \%)$, hyperactivity $(8.4 \%)$, conduct disorder $(32.9 \%)$, and peer problems (13.1\%). The prevalence of EBPs among adolescents in Turkey is $16.9 \%$ [8] and $10 \%$ in USA [9].

Behavioral and emotional problems among the adolescents are influenced by different factors such as knowledge, self-efficacy, and psychosocial skills. Factors correlating with EBP are also psychosocial skills, parenting, and stressors in the family [10]. Umami et al. (2019) also report that social loneliness and peer relations are factors correlating with EBP among adolescents in Indonesia [7]. Other different factors such as age, sex, family economic level, and father's education are also reported to correlate with EBP among adolescents (mean: 11.56 years old) in China [11]. Furthermore, inadequate intra-familial communication and parental mental disorder factors are also factors contributing to EBP among Indian adolescents [12]. 
Furthermore, factor correlating with EBP among adolescents is self-efficacy. Higher the selfefficacy level helps to control the anti-social behavior. Psychosocial skills including social skills, thinking skills, and emotional skills are also reported to correlate with EBPs. Self-efficacy is also found to correlate with psychosocial well-being such as to help manage social life [13]. High social competence and skills can help adolescents develop coping strategies. Efforts to improve psychosocial skills affect the mental health of adolescents [14].

The Social Protection and Rehabilitation Centre for Adolescents (SPRCA) is an institution that coaches' adolescents with social and legal problems in the Special Region of Yogyakarta (DIY). The legal case mostly found among adolescents in BPRSR is theft $(57.7 \%)$. The Class I of the Guidance Institution for Children (GIC) in Kutoarjo is an institution that coaches' children who have problems with the law. The GIC is an institution under the Regional Office of the Ministry of Law and Human Rights of Central Java Province. The most frequent case found among adolescents in the GIC is persecution ( $48.5 \%)$.

The purpose of this study is to determine factors that correlate with the EBP among adolescents who have problems with the law.

\section{Methods}

\section{Study design, setting, and samples}

This research was a cross-sectional study. Fifty-nine adolescents with legal problems served as respondents. The inclusion criteria in this study were (1) adolescents of 15-19 with legal problems and were being trained at the SPRCA, DIY and GIC of Kutoarjo, Purworejo, (2) those who were willing to become respondents, and (3) those who obtain permission from the guardians/officers at the SPRCA and GIC. The exclusion criteria in this study were those who had severe depression based on the psychological records and recommendations from the SPRCA and GIC.

\section{Ethical consideration}

Ethical clearance was obtained from Ethical Committee of the Faculty of Medicine, Public Health and Nursing of Universitas Gadjah Mada (ethic number: KE/FK/0330/EC/2019).

\section{Instruments}

The Strengths and Difficulties Questionnaire (SDQ) developed by Goodman was used to measure the EBPs among adolescents [15], [16]. The SDQ had been translated into Indonesian and was once used by Wiguna and Hestyanti; it is available at https:// www.sdqinfo.org/[17], which consisted of 25 items with five domains: Emotional problems, peer problems, behavioral problems, hyperactivity, and pro-social behavior. The questionnaire was developed based on the Likert scales with the criteria of 2 for correct, 1 for somewhat correct, and 0 for incorrect. There were five unfavorable items with reversed scoring, namely, items $7,11,13,21$, and 25 . The EBP were calculated from the total score of difficulties (the sum of emotional problems, peer problems, behavioral problems, and hyperactivity). The higher the score of the total difficulties, the higher the EBPs level. Each domain was classified into three criteria: Normal, borderline, and abnormal (Table 1).

Table 1: Cut off point SDQ

\begin{tabular}{llll}
\hline Domain SDQ & Normal & Borderline & Abnormal \\
\hline Emotional problem & $0-3$ & 4 & $5-10$ \\
Behavioral problem & $0-2$ & 3 & $4-10$ \\
Hyperactivity & $0-5$ & 6 & $7-10$ \\
Peer problem & $0-2$ & 3 & $4-10$ \\
Total difficulties & $0-13$ & $14-16$ & $17-40$ \\
Pro social & $6-10$ & 5 & $0-4$ \\
\hline SDQ: Strength and difficulties questionnaire. & &
\end{tabular}

Questionnaires about the knowledge of psychosocial skills created by Penyami (2020) that are referred to the book of Communication, Information, and Education of the Adolescent Health Cadre of the Ministry of Health (2018) are composed of about ten psychosocial skills of the adolescents [18]. The questionnaires consisted of 25 items and had passed the validity and reliability tests with good results $(r=$ $0.216-0.448$ and consistency value $=0.705$ ). The selfefficacy questionnaires consisted of 46 items covering magnitude, generality, and strength [19]. The validity of the self-efficacy questionnaire ranged from 0.306 to 0.605 and the internal consistency value was 0.900 [18].

Pearson Product Moment was used to analyze the correlations between the independent variables and the EBPs among adolescents. The linear regression test was used to determine the factors correlating with the EBP. One similar research also shows that age and gender influence the occurrence of EBP among the orphans [20].

\section{Data collection}

This research was conducted in May 2019 at the SRB of the Special Region of Yogyakarta and GIC of Kutoarjo, Purworejo, Central Java. The data were collected after the research permit and ethical clearance were obtained.

\section{Data analysis}

\section{Bivariate analysis}

The Pearson Product Moment was used to examine the correlations of age, knowledge, selfefficacy, and psychosocial skills of adolescents with 
EBPs. The one-way ANOVA test determines the correlations of education, types of legal problems, and length of assistance with EBPs.

\section{Multivariate analysis}

The multivariate analysis used was linear regression with the backward method. In this method, all selected variables were included in the multivariate analysis, and the insignificant variables were excluded from the analysis gradually. The linear regression analysis started with selecting the candidates for the multivariate test in the variables with $p<0.25$.

\section{Results}

\section{Participants' background}

The average age of the respondents was $16.89 \pm 1.16$ years old and $94.91 \%$ of them are male adolescents. The most frequent legal case is persecution, theft, sexual abuse, and drug abuse consecutively (Table 2).

Table 2: Characteristic of adolescents with legal problem at SPRCA and GIC ( $n=59)$

\begin{tabular}{|c|c|c|c|}
\hline Karakteristik & Mean \pm SD & Min-Max & $F(\%)$ \\
\hline Age & $16.89 \pm 1.16$ & $15-19$ & \\
\hline \multicolumn{4}{|l|}{ Sex } \\
\hline Male & & & $56(94.91)$ \\
\hline Female & & & $3(5.09)$ \\
\hline \multicolumn{4}{|l|}{ Educational background } \\
\hline Did not graduated elementary school & & & $2(3.39)$ \\
\hline Elementary school & & & $21(35.59)$ \\
\hline Junior high school & & & $29(49.15)$ \\
\hline Senior high school & & & $7(11.86)$ \\
\hline \multicolumn{4}{|l|}{ Legal problems } \\
\hline Sexual abuse & & & $14(23.7)$ \\
\hline Theft & & & $17(28.8)$ \\
\hline Drug abuse & & & $6(10.2)$ \\
\hline Persecution & & & $22(37.3)$ \\
\hline \multicolumn{4}{|l|}{ Length of Guidance } \\
\hline $1-3$ months & & & $38(64.4)$ \\
\hline$>3-6$ months & & & $10(16.9)$ \\
\hline$>6-12$ months & & & $7(11.9)$ \\
\hline$>12$ months & & & $4(6.8)$ \\
\hline
\end{tabular}

\section{The emotional and behavioral problems among adolescents with legal problems}

The prevalence of the EBP among adolescents with legal problems is $67.8 \%$. The prevalence of the emotional problems, behavioral problems, hyperactivity, and peer problems is $67.8 \%$, $64.4 \%, 13.6 \%$, and $57.6 \%$, respectively (Table 3 ). There are correlations between age and psychosocial skills with the EBP among these adolescents (Table 4). Age is the most dominant factor correlating with the EBP among these adolescents. Age and psychosocial skills make $15.7 \%$ of the EBP among these adolescents (Table 5).
Table 3: EBP in adolescents with legal law at SRCA and GIC ( $n=59)$

\begin{tabular}{llll}
\hline Emotional and behavioral problems & Normal F (\%) & Borderline F (\%) & Abnormal F (\%) \\
\hline Emotional problem & $13(22)$ & $6(10.2)$ & $40(67.8)$ \\
Behavioral problem & $16(27.1)$ & $5(8.5)$ & $38(64.4)$ \\
Hyperactivity & $39(66.1)$ & $12(20.3)$ & $8(13.6)$ \\
Peer problem & $14(23.7)$ & $11(18.6)$ & $34(57.6)$ \\
Total of SDQ & $13(22)$ & $6(10.2)$ & $40(67.8)$ \\
Pro social & $32(54.2)$ & $3(5.1)$ & $24(40.7)$ \\
\hline EBPs: Emotional and Behavioral Problems, GIC: Guidance Institution for Children, SDQ: Strengths and
\end{tabular}
Difficulties Questionnaire.

\section{Discussion}

The main findings of this study are that the age and psychosocial skills of the adolescents contribute to the EBP of as much as $15.7 \%$. The results of a previous study have indicated that gender, communication, social loneliness, peer relationships, and social support influence the EBP among adolescents in Indonesia by $18.2 \%$ [7]. Inadequate family communication and parental mental disorder affect the EBPs for as much as $12.8 \%$ [12]. The psychosocial skills in this study include self-awareness, empathy, interpersonal relationships, effective communication, critical thinking, creative thinking, problem solving, decision making skills, skills in dealing with stress, and emotional control skills [21]. A similar study reports that there is a correlation between age and EBP among the adolescents [11], [21].

Table 4: Correlation between independent variables with $\operatorname{EBP}(n=59)$

\begin{tabular}{|c|c|c|c|c|}
\hline \multirow[t]{2}{*}{ Variable } & \multicolumn{4}{|c|}{ Emotional and behavioral problems } \\
\hline & $\mathrm{r}$ & $\mathrm{p}$ & Mean \pm SD & $\mathrm{p}$ \\
\hline Age & -0.373 & $0.004^{\star \star \#}$ & & \\
\hline Knowledge & -0.064 & $0.632^{\#}$ & & \\
\hline Self-Efficacy & -0.127 & $0.339^{\#}$ & & \\
\hline Psychosocial Skill & -0.294 & $0.024^{\star *}$ & & \\
\hline \multicolumn{5}{|l|}{ Educational Background } \\
\hline Did not graduated Elementary School & & & $20.50 \pm 6.36$ & $0.851^{\pi}$ \\
\hline Elementary school & & & $20.23 \pm 6.90$ & \\
\hline Junior High School & & & $18.41 \pm 7.70$ & \\
\hline Senior High School & & & $16.00 \pm 7.70$ & \\
\hline \multicolumn{5}{|l|}{ Kind of problems } \\
\hline Sexual abuse & & & $17.77 \pm 7.81$ & $0.900^{\pi}$ \\
\hline Theft & & & $20.58 \pm 6.69$ & \\
\hline Drug abuse & & & $15.16 \pm 2.35$ & \\
\hline Persecution & & & $18.84 \pm 6.95$ & \\
\hline \multicolumn{5}{|l|}{ Length of Guidance } \\
\hline $1-3$ months & & & $18.26 \pm 6.90$ & $0.605^{\pi}$ \\
\hline$>3-6$ months & & & $20.90 \pm 7.60$ & \\
\hline$>6-12$ months & & & $16.28 \pm 6.67$ & \\
\hline$>12$ months & & & $23.75 \pm 4.11$ & \\
\hline
\end{tabular}

The results of this study indicate that the total difficulty experienced by the adolescents with legal problems reaches $67.8 \%$. The total difficulty found among the adolescents in India is 40\% [4], 78.6\% among children of $11-13$, and $40 \%$ among children of $14-17$ in New Zealand [22], 25.7\% among the adolescents in Pakistan [23], and $34.4 \%$ of the adolescents with

Table 5: Linear regression predicting of Adolescents' emotional and behavioral problems

\begin{tabular}{lllll}
\hline Factors & $\mathrm{B}$ & $(95 \% \mathrm{Cl})$ & $\mathrm{p}$ & ${\text { Adjusted } \mathrm{R}^{2}}^{2}$ \\
\hline Psychosocial skill & -0.223 & $-0.704-0.037$ & 0.077 & 15.7 \\
Age & -0.324 & $-3.395--0.453$ & 0.011 & \\
\hline
\end{tabular}

Congenital Heart Disease in the Netherlands [24]. The results of a similar study also show that $40.5 \%$ of children of 5-14 who suffer from lower urinary tract 
dysfunction are reported to have the EBPs [25]. The results of this study indicate that adolescents with legal problems who have emotional problems and conduct disorder are $67.8 \%$ and $64.4 \%$ respectively. Lambie et al. (2017) reported $42.9 \%$ and $78.6 \%$ of children of 11-13 experience emotional problems and conduct disorder [22]. One previous study report that conduct disorders have been experienced by $26.54-42 \%$ of the adolescents in India [6], [4]. Emotional problems have also occurred among $34 \%$ of the adolescents in India [4] and 25.9\% of the adolescents in Pakistan [23].

As many as, $13.6 \%$ of the adolescents in this study show hyperactivity. It is experienced by $8.4 \%$ of the adolescents in Indonesia [7], 24\% of the adolescents in India [4], and $23.1 \%$ of the adolescents in Pakistan [23]. It has also been identified among $29 \%$ of children suffering from lower urinary tract dysfunction [25]. The prevalence of peer problems found among adolescents in this study is $57.6 \%$. Peer problems are reported to be experienced by $42 \%$ of adolescents in India [4]. We conclude that the finding of the study is age and psychosocial skills correlate with the EBPs of the 15-19 years old adolescents who have legal problems.

We found that adolescent psychosocial skills were the most dominant factor associated with EBP. A similar study was conducted to Portuguese adolescents showed that psychosocial skills were negatively correlated with EBPs [26]. Psychological skills can be increased of psychological well-being. Furthermore adolescents with psychological well-being can be increased cooperative skill and decreased of mental health problems [27]. Poulou (2012) also reported that adolescents with strong social skill were less likely to present emotional and behavioral difficulties [28]. Psychosocial intervention such as cognitive behavioral therapy and interpersonal therapy evident effective for decrease depression and increase of Psychosocial skill of adolescents [29], [30].

There are several limitations of this study. First, the results of this study were based on the reports from adolescents. The assessment of EBPs would be more effective if it was obtained from a variety of informants. Second, the respondents were not randomly selected. Not all adolescents had the same opportunity to become respondents. In determining the respondents, the researcher paid attention to the inclusion criteria and exclusion criteria that had been determined. Third, this study did not measure the demographic data of the families or relatives who lived with the adolescents, such as the socioeconomic status, the mental health status, and the education level. Despite these limitations, this study should be useful to help design appropriate interventions for adolescents with legal problems and for those living in rehabilitation and support centers.

The results of this study show practical implications for improving the psychosocial skills of adolescents who are dealing with law cases. In this study, the psychosocial skills are a factor that can be associated with their EBPs. Therefore, health workers (psychologists or other health workers) can determine priority interventions. Adolescents who are dealing with law cases and stay in rehabilitation or support centers are at risk of increasing EBPs. Staying in a rehabilitation or support centers contribute more to the rise of emotional and behavioral problems rather than staying in the previous condition. To eliminate stigma and discrimination, they require more intensive and varied interventions.

We recommend that rehabilitation or support centers add training in psychosocial skills including self-awareness, empathy, interpersonal relationships, effective communication, critical thinking, creative thinking, problem solving, decision making skills, skills in dealing with stress, and emotional control skills. In addition to this, it is necessary to strengthen the support of both the family and peers. Parental involvement can prevent or reduce EBPs. Interventions that involve parents and peers will reduce the EBPs.

\section{Conclusion}

Age and psychosocial skills correlate with the EBP among adolescents with legal problems at the SPRCA and GIC. It is necessary to develop interventions to improve psychosocial skills, therefore that the risk of EBPs among adolescents can be reduced. All parties involved in caring children and adolescents, including parents, teachers, other professionals, and the community, have a strategic responsibility to promote and provide support when needed it. Besides, to increase interaction of adolescents who are dealing with law cases and stay in rehabilitation or support centers with their parents, the government should make a regulation regarding the visiting hours for parents.

\section{Acknowledgments}

We were grateful to Universitas Gadjah Mada for supporting funding. We would also like deeply thank to adolescents for their participating.

\section{References}

1. Umbach R, Raine A, Leonard NR. Cognitive decline as a result of incarceration and the effects of a cbt/mt intervention: A clusterrandomized controlled trial. Crim Justice Behav. 2018;45(1):3155. https://doi.org/10.1177/0093854817736345 PMid:29795707

2. Zilanawala A, Sacker A, Kelly Y. Longitudinal latent cognitive profiles and psychosocial well-being in early adolescence. J Adolescent Health. 2017;61(4):493-500. https://doi. org/10.1016/j.jadohealth. 2017.05.008 PMid:28732718

3. BistaB, Thapa P, SapkotaD, Singh SB, PokharelPK. Psychosocia problems among adolescent students: An exploratory study in the Central region of Nepal. Front Public Health. 2016;4(8):1-7. 
https://doi.org/10.3389/fpubh.2016.00158

4. Umamaheswati K, Suja MK. Behavioral and emotional problems of children under institutional care in Coimbatore District of Tamil Nadu. Indian J Community Health. 2019;31(2):273-8.

5. Chen YY, Ho SY, Lee PC, Wu CK, Gau SS. Parent-child discrepancies in the report of adolescent emotional and behavioral problems in Taiwan. PLoS One. 2017;12(6):1-12. https://doi.org/10.1371/journal.pone.0178863

\section{PMid:28644832}

6. Edlina K, Arif A, Nilesh GM, Sonia DP. Prevalence of emotional, behavioral problems and ego resilience among tea tribe adolescents living in Disbruagarh district of Assam. Clin Epidemiol Glob Health. 2019;2019:12. https://doi.org/10.1016/j. cegh.2019.06.012

7. Umami R, Turnip SS. Emotional and behavioral problems among left-behind Children in Indonesia. Indian J Psychol Med. 2019;41(2):240-5. https://doi.org/10.4103/JJPSYM.IJPSYM_370_18 PMid:31142925

8. Avci D, Selcuk KT, Kaynak S. The Magnitude and determinants of emotional behavioral problems in working adolescents in Turkey. Arch Psychiatr Nurs. 2018;32(1):44-50. http://dx.doi. org/10.1016/j.apnu.2017.09.011

PMid:29413071

9. Turer $\mathrm{CB}$, Lin H, Flores $\mathrm{G}$. Health status, emotional/behavioral problems, health care use, and expenditures in overweight/ obese US children/adolescents. Acad Pediatr. 2013;13(3):2518. http://dx.doi.org/10.1016/j.acap.2013.02.005 PMid:23680342

10. Aebi M, Giger J, Plattner B, Metzke CW, Steinhausen HC. Problem coping skills, psychosocial adversities and mental health problems in children and adolescents as predictors of criminal outcomes in young adulthood. Eur Child Adolesc Psychiatry. 2014;23(5):283-93. https://doi.org/10.1007/ s00787-013-0458-y

PMid:23949100

11. Song Y, Li L, Xu Y, Pan G, Tao F, Ren L. Associations between screen time, negative life events, and emotional and behavioral problems among Chinese children and adolescents. JAffect Disord. 2020;264:506-12. https://doi.org/10.1016/j.jad.2019.11.082

PMid:31757618

12. Aboobaker $\mathrm{S}$, Jangam KV, Sagar KJ, Amaresha AC, Jose A. Predictors of emotional and behavioral problems among Indian Adolescents: A clinic-based study. Asian J Psychiatry. 2019;39:104-9. https://doi.org/10.1016/j.ajp.2018.12.002

13. Caroli ME, Sagone E. Generalized self-efficacy and well-being in adolescents with high vs. low scholastic self-efficacy. Proc Soc Behav Sci. 2014;141:867-74. https://doi.org/10.1016/j. sbspro.2014.05.152

14. Jamali S, Sabokdast S, Nia HS, Goudarzian AH, Beik S, Allen KA. The effect of life skills training on mental health of Iranian middle school students: A preliminary study. Iran J Psychiatry. 2016;11(4):269-73.

15. Goodman R. The strengths and difficulties questionnaire: A research note. J Psychology Psychiatry. 1997;38(5):581-6. PMid:9255702

16. Goodman R. Psychometric properties of the strengths and difficulties questionnaire. J Am Acad Child Adolesc Psychiatry. 2001;40(11):1337-45. https://doi. org/10.1097/00004583-200111000-00015 PMid:11699809

17. SDQ Information for Researchers and Professionals About the Strengths and Difficulties Questionnaires. Available from: https://www.sdqinfo.org. [Last accessed on 2021 May 21].
18. Penyami $Y$, Hartini S, Prabandari YS. The effectiveness of health education with audiovisual media on the psychosocial skills of adolescents in trouble with the law. Indian J Public Health Res Dev. 2020;11(4):846-51. https://doi.org/10.1016/j. enfcli.2018.11.013 PMid:30745163

19. Bandura A. Guide for Constructiong Self-efficacy Scales; 1997. https://doi.org/10.1017/CBO9781107415324.004

20. Ashiq U, Saleem S, Jabeen A, Mahmood Z. Identity and emotional behavior problems in institutionalized orphans and mainstraim adolescents. J Pak Psychiatr Soc. 2019;16(2):36-40.

21. Simsek Z, Erol N, Oztop D, Munir K. Prevalence and predictors of emotional and behavioral problems reported by teachers among institutionally reared children and adolescents in Turkish orphanages compared with community controls. Children Youth Serv Rev. 2007;29(7):883-99. https://doi.org/10.1016/j. childyouth.2007.01.004

PMid:25520538

22. Lambie I, Krynen, A. The utility of the strengths and difficulties questionnaire as a screening measure among children and adolescents who light fires. J Forensic Psychiatry Psychol. 2017;28(3):313-30. http://dx.doi.org/10.1080/14789949.2016.1 275747

23. Zafar S, Johar N, Haseeb F, Azam N, Mahmood H, Pervaiz F. Prevalence of socio-emotional problems in school-aged adolescents of Army Public Schools of Rawalpindi. Pak Armed Forces Med J. 2019;69(Suppl 2):S181-6.

24. Spijkerboer AW, Utens EM, Bogers AJ, Verhulst FC, Helbing WA. Long-term behavioural and emotional problems in four cardiac diagnostic groups of children and adolescents after invasive treatment for congenital heart disease. Int $\mathrm{J}$ Cardjol. 2008;125(1):66-73. http://dx.doi.org/10.1016/j.ijcard.2007.02.025 PMid:17433472

25. Dourado ER, Abreu GE, Santana JD, Macedo RR, Silva CM, Rapzo PM, et al. Emotional and behavioral problems in children and adolescents with lower urinary tract dysfunction: A population based study. J Pediatr Urol. 2019;15:376. e1-7. https://doi.org/10.1016/j.jpurol.2018.12.003

PMid:31471270

26. Campos J, Barbosa-Ducharne M, Dias P, Rodrigues $S$, Martins AC, Leal M. Emotional and behavioral problems and psychosocial skills in adolescents in residential care. Child Adolesc Soc Work J. 2019;36:237-46. https://doi.org/10.1007/ s10560-018-0594-9

27. Holopainen L, Lappalainen $\mathrm{K}$, Junttila $\mathrm{N}$, Savolainen $\mathrm{H}$. The role of social competence in the psychological well-being of adolescents in secondary education. Scand J Educ Res. 2012;56(2):199-212. http://dx.doi.org/10.1080/00313831.2011.581683

28. Poulou MS. How are trait emotional intelligence and social skills related to emotional and behavioral difficulties in adolescents? Educ Psychol. 2014;34(3):354-66. http://dx.doi.org/10.1080/014 43410.2013.785062

29. David-Ferdon C, Kaslow NJ. Evidence-based psychosocial treatments for child and adolescent depression. J Clin Child Adolesc Psychol. 2008;37(1):62-104. https://doi. org/10.1080/15374410701817865 PMid:18444054

30. Penyami Y, Prabandari YS, Hartini S. Pengaruh Pendidikan Kesehatan dengan Media Audiovisual terhadap Pengetahuan, Efikasi Diri dan Ketrampilan Psikososial Remaja di BPRSR Yogyakarta. (The Impact of Health Education using the Audiovisual Media on Knowledge, Self-Efficacy, and Psychosocial Skill of Teenagers in SPRCA Yogyakarta). (Master's Thesis). Universitas Gadjah Mada, Yogyakarta, Indonesia; 2019. 